1 Designer de Ambientes. Mestre em Design, Inovação e Sustentabilidade pela Universidade do Estado de Minas Gerais (UEMG). Professora titular na UEMG. | E-mail: nadjamourao@gmail.com.

2 Mestre em Engenharia de Produção pela PUC-Rio. Doutora em Engenharia de Produção e Gestão de Inovação Tecnológica pela Ecole Centrale Paris (ECP), França. Professora titular na UEMG. | E-mail: rcengler@uol. com.br.

\section{A TECNOLOGIA SOCIAL E OS TEMAS ASSOCIADOS: UM OLHAR SOB O TRABALHO ARTÍSTICO DE TOBBE MALM}

\section{SOCIAL TECHNOLOGY AND ASSOCIATED THEMES: A LOOK AT THE ARTISTIC WORK OF TOBBE MALM}

\author{
Nadja Maria Mourão ${ }^{1}$ \\ Rita de Castro Engler ${ }^{2}$
}

RESUMO: Esse artigo apresenta uma breve descrição de temáticas que se associam à tecnologia social, como: a natureza da tecnologia, o saber prático e o saber tecnológico e as relações de trabalho. Busca-se relacionar os conteúdos abordados ao trabalho artístico de Tobbe Malm. Como ferreiro, o artista dá formas humanizadas a parafusos e peças de metal, que independente de suas formas, são carregadas de emoções. O Artista criou o Projeto Ferreiro Internacional Iron Rose, inspirado nas rosas colocadas nas ruas, após o trágico evento de ataques terroristas em Oslo e Utøya, em 22 de julho de 2011. Ao relacionar o trabalho de Tobbe Malm com as temáticas associadas à tecnologia social, foi observado que em cada etapa de vida do artista suas iniciativas e projetos se convergem aos conteúdos. A relação de transformação da forma do parafuso com o saber prático e científico condiz com a associação emocional, produzida pelo trabalho artístico, utilizando o ferro. Sabe-se que o parafuso carrega uma parcela do processo de evolução da tecnologia, e a intervenção do artista associa ao mesmo outra vertente da vida humana, tornando-o um trabalho inovador.

PALAVRAS-CHAVE: Tecnologia Social, Temáticas Sociais, Trabalho Artístico, Tobbe Malm, Arte.

ABSTRACT: This article presents a brief description of the themes associated with social technology, such as: the nature of technology, practical knowledge and technological know-how, and labor relations. It attempts to relate the contents addressed in the artistic work of Tobbe Malm. As a blacksmith, the artist gives humanized forms to bolts and pieces of metal, which, regardless of their forms, are loaded with emotions. The Artist created the Iron Rose International Blacksmith Project, inspired by the roses placed on the streets after the tragic event of the terrorist attacks in Oslo and Utøya on July 22, 2011. By relating the work of Tobbe Malm to the themes associated with social technology, It was observed that in each stage of the artist's life, his initiatives 
and projects converge to the contents. The relation of transformation of the shape of the screw with practical and scientific knowledge is consistent with the emotional association produced by the artistic work using iron. It is known that the screw carries a part of the process of evolution of technology, and the intervention of the artist associates with it another strand of human life, turning it into an innovative work.

KEYWORDS: Social Technology, Social Themes, Artistic Work, Tobbe Malm, Art.

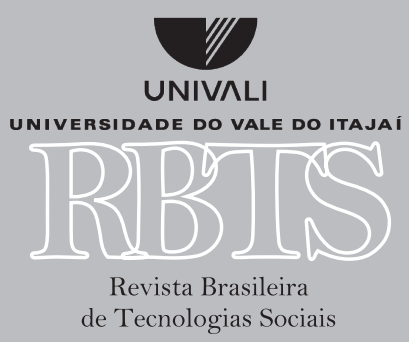




\section{INTRODUÇÃO}

Desde sempre a humanidade se apropria dos recursos do planeta que garantia e ainda garante a sua existência. Nos últimos tempos, mudanças na esfera terrestre ocorrem em constante ímpeto, provocando situações de emergências. A humanidade, consciente da globalização e habituada à aceleração deste sistema, permanece perplexa pela incoerência de métodos de produtividade gerados pelo capitalismo.

Em resposta às necessidades da dinâmica emergente na vida humana, são promovidas mudanças em diversas áreas que estimulam o surgimento de novas configurações organizacionais. Pucci (1994) considera que os avanços tecnológicos e a crescente competitividade em escala global estão transformando as instituições em tempo real, ocorrendo controle do desenvolvimento de produtos, serviços e informação, cujas tarefas crescem em importância e complexidade.

Os desafios assumidos por uma sociedade tecnológica, cujos aspectos se modificam rapidamente, confirmam a percepção de Halévy (1961) a respeito da Aceleração da História ${ }^{1}$. Vivencia-se uma nova realidade planetária, em busca dos complexos caminhos para soluções que atendam às diversas áreas, que possam amenizar e simplificar os efeitos que se alastram em meio à superpopulação.

A percepção da velocidade da vida é instantânea, onde novos estilos e formas sociais de convivência se instalam a cada momento. Um indivíduo pode transitar pela superfície do planeta sem precisar sair fisicamente do lugar. Os grupos sociais deixam de ser uma questão somente local e passam a ser mundial. As tecnologias da informação e comunicação permitem a interatividade social em potencial que estimulam a cultura num processo irreversível, conforme Castells (2009).

O modelo capitalista vigente possibilita a expansão da economia e das novas riquezas, mas gera também a pobreza e a desigualdade entre os povos. Santos (2000) considera que, na vida em sociedade, os sistemas técnicos e políticos se confundem por meio de combinações oriundas das escolhas. São consequências dos povos e das nações em determinados momentos e lugares, em que a história e a geografia se fazem e refazem continuamente.

Ao refletir sobre as escolhas e as atitudes que definem o uso dos recursos para produtos e serviços, atribuem-se à humanidade as implicações da realidade estabelecida. Manzini (2008) relata que os produtos gerados ao longo da história possuem enormes vantagens de conforto e qualidade, fato justificado pelos procedimentos de produção. No entanto, os atuais processos geram imensuráveis desperdícios em todos os setores em ciclos autodestruidores.

É evidente que o processo de evolução das tecnologias reconduziu o destino dos povos e, por conseguinte, das nações. Kazazian (2005) evidencia o questionamento de quais os meios devem ser utilizados para satisfazer às necessidades humanas. Observa-se que há dicotomia entre os modelos de vida e os valores culturais, econômicos e sociais, apontando os métodos de produção em diferentes grupos sociais.

Dessa forma, pode haver soluções que atendam às necessidades humanas, mas que preservem as relações e o contexto sociocultural sob as bases da tecnologia social.

As tecnologias sociais se apresentam como soluções atuais, simples e de baixo custo, as quais se popularizaram como alternativas para a resolução das questões estruturais da sociedade,

1 Halély (1961) relata que nenhuma sociedade é um sistema estacionário, mas uma realidade em transformação incessante, uma realidade cuja estrutura e organização estão constantemente modificando. Ou seja, subitamente tudo está mudando em torno dos homens, durante sua vida. 
principalmente de grupos menos favorecidos. Nelas, encontram-se possibilidades efetivas para problemas nas áreas da educação, inclusão social, meio ambiente, energia, alimentação, habitação, saúde, trabalho, entre outros. Estão fundamentadas em duas proposições importantes para sua propagação: a participação das pessoas das comunidades que as desenvolvem e a sustentabilidade nas soluções apresentadas, conforme Costa (2013).

Esse artigo, sem a pretensão de abranger todas as investigações em conceitos e teorias, apresenta uma breve descrição de temáticas que se associam à tecnologia social, relacionando-as ao trabalho artístico de Tobbe Malm. Os temas abordados em bases conceituais são: a natureza da tecnologia, o saber prático e o saber tecnológico e as relações de trabalho.

Tobbe Malm é um artista, ferreiro, escultor, fotógrafo, que busca transformar simples formas de parafusos em arte. Os trabalhos de Tobbe Malm são inspirações para a pesquisa por apresentar a sensibilidade humana por meio de um material tão sólido quanto o ferro. Em formas de parafusos, as técnicas e os recursos transmitem a emoção das atividades e das relações humanas, constituindo a série denominada Bolt Poetry.

\section{A NATUREZA DA TECNOLOGIA}

A realidade que cerca a humanidade está imersa num mundo construído, e constituído, por artefatos tecnológicos, repletos de interferências humanas que transformam e metamorfoseiam o território, o tempo, os valores, o cotidiano, as relações e a sua própria existência, conforme Gianolla (2008).

Segundo Zuben (1993), o ser humano habita o mundo por dois modos básicos: por meio da ação (praxis) e pela compreensão. Habitar o mundo implica para o homem, conforme as circunstâncias, ter à sua disposição os utensílios necessários para produzir sua existência. Estabelece-se uma homeostase entre o homem e a realidade. A arte de explorar o meio e sobreviver ao ambiente natural começa a receber a ajuda de instrumentos e técnicas por volta de 40.000 anos antes do presente momento, conforme Cardoso (2001).

O desenvolvimento da técnica está intimamente relacionado com o que conhecemos da história do ser humano na Terra, com as determinações sociais, políticas, econômicas e culturais, pois estas constroem uma relação histórica do homem com a natureza, no esforço humano de criar instrumentos que superem as dificuldades impostas pelas forças naturais. (CARDOSO, 2001, p.185).

As técnicas são um conjunto de meios instrumentais e sociais, com os quais o homem realiza sua vida, produz e, ao mesmo tempo, cria espaço. "O conceito de conhecimento técnico - techné, de origem grega, que o considerava como a contemplação da realidade e em resolver problemas práticos”, por habilidades manuais, conforme Santos (1999, p.25).

A humanidade vive no mundo da tecnosfera. Isso significa dizer que a tecnologia representa o modus vivendi da sociedade atual. Ou seja, tudo que materialmente circunda a vida das pessoas diz respeito à tecnologia. Miranda (2002) afirma que a tecnologia moderna não pode ser considerada um mero estudo da técnica.

A tecnologia é fruto da aliança entre ciência e técnica, a qual produziu a razão

instrumental, como no dizer da Teoria Crítica da Escola de Frankfurt. Esta aliança proporcionou o agir-racional-com-respeito-a-fins, conforme assinala 
Habermas, a serviço do poder político e econômico da sociedade baseada no modo de produção capitalista (séc. XVIII) que tem como mola propulsora o lucro, advindo da produção e da expropriação da natureza. Então, se antes a razão tinha caráter contemplativo, com o advento da modernidade, ela passou a ser instrumental. É nesse contexto que deve ser pensada a tecnologia moderna; ela não pode ser analisada fora do modo de produção, conforme observou Marx. (MIRANDA, 2002, p. 51, grifo da autora).

O termo "tecnologia" se popularizou, no entanto se questiona sobre os princípios que definem e regem o seu funcionamento. Os estudos interdisciplinares de Arthur (2009) questionam e analisam assuntos como a teoria das origens e evolução da tecnologia, fazendo uma correspondência entre a teoria de Darwin sobre a seleção natural, em análises comparativas sobre a invenção de novas tecnologias.

Arthur (2009) relata sobre o processo de transformação, em que cada tecnologia apresenta soluções para problemas, mas que também gera novos problemas, o que exigirá outras tecnologias para resolvê-los. Entre outras perguntas, o autor questiona: "como as tecnologias existentes dão origem às novas tecnologias?”. Quer saber se "há uma unidade subjacente à variedade aparentemente desconcertante de tecnologias? Há um mecanismo para explicar a origem da inserção de novas tecnologias?” (ARTHUR, 2009, p.13).

Arthur (2009) expõe diferentes definições de tecnologia nos níveis do macro e micro e afirma que é um meio para realizar um propósito humano, ou seja, intencional. Outra definição ampla trata a tecnologia como um conjunto de práticas e componentes. E a terceira definição do autor é que a tecnologia pode ser considerada como o conjunto de dispositivos e práticas de engenharia disponíveis para a cultura. Nos níveis micro, toda tecnologia moderna é composta por subtecnologias², a qual, por sua vez, é constituída de outras subtecnologias.

Conforme a avaliação dos frankfurtianos ${ }^{3}$, na evolução da sociedade, o ser humano tornou-se escravo da tecnologia. Precisa-se redefinir qual a função social da ciência, da técnica e da tecnologia. É necessário dirigir a razão (o pensar) para a emancipação do homem e também conduzir a razão com uma maior autonomia da ciência, segundo Miranda (2002).

Uma tecnologia utilizada no início da evolução humana, como um arco e flecha, depende do fato de que a energia pode ser armazenada em materiais elásticos. Outras tecnologias, como invenções mecânicas, dependem de leis físicas relacionadas ao movimento e à força. Por outro lado, a tecnologia moderna envolve a programação dos fenômenos que não estão disponíveis aos sentidos humanos comuns. Assim, o conhecimento científico é, geralmente, um pré-requisito para o avanço tecnológico, conforme Arthur (2009).

A tecnologia permite descobrir mais sobre a natureza das leis da física, e que o conhecimento pode, então, ser utilizado para criar uma nova tecnologia, que pode ser utilizada para refinar mais o conhecimento científico e assim por diante.

Arthur (2009) afirma que a tecnologia é um fenômeno capturado e posto em uso. Para o autor, as tecnologias possuem hierárquicas estruturas, como tecnologias em um nível superior direto,

2 Componentes e rede de tecnologias funcionam por programação de fenômenos naturais, por exemplo, o campo da eletrônica depende de leis físicas, conforme Arthur (2009) .

3 Refere-se a um grupo de intelectuais e a uma teoria social. O termo busca designar a institucionalização dos trabalhos de um grupo de intelectuais marxistas, não ortodoxos, que na década de 1920 permaneceram à margem de um marxismo clássico, conforme Miranda (2002). 
por exemplo, em um programa de computador. Cada subtecnologia, provavelmente, inicia-se por uma específica atividade, mas que pode ser adaptada para um novo uso, gerando uma nova tecnologia. Qualquer componente da tecnologia é em si uma tecnologia em miniatura, conforme Arthur (2009).

Um parafuso, por exemplo, é mais do que um elemento de fixação empregado na união não permanente de peças. Ou seja, as peças fixadas por parafusos podem ser montadas e desmontadas facilmente. Contudo, um parafuso em si carrega uma parcela do processo de evolução da tecnologia. A função de rosquear é uma operação agregada a outras funções determinantes. Cita-se, como exemplo, o sistema de bombeamento e de elevação de água, denominado como “parafuso de Arquimedes”, utilizado na antiguidade, conforme Maroyer e Roudart (2008).

\section{O SABER PRÁTICO E O SABER TECNOLÓGICO}

A denominação de prática vem do seu objeto de tratamento, que consiste nas coisas praticáveis, ou seja, nas ações humanas, conforme metodologia das disciplinas práticas no pensamento do filósofo Aristóteles.

Segundo Lins (2003), o saber prático trata do conhecimento do fazer, das experiências e dos esforços na problemática da transferência de saber "prático". Saber prático ou know-how é a habilidade de saber colocar em ação o conhecimento prévio em circunstâncias específicas. $\mathrm{O}$ saber prático inato envolve a utilização simultânea de habilidades manuais, motoras, cinéticas, cognitivas, de linguagem e, principalmente, experiência como o uso de intuição e de julgamento. Ou seja, saber prático é inseparável da ação específica, relacionado a uma situação concreta, ligado diretamente a tradições prevalecentes (por exemplo, tradições sobre a forma de realizar determinadas atividades operacionais) e, principalmente, é inseparável da pessoa que o possui.

Lins (2003) relata que, como é um processo social, o nível de confiança entre os atores envolvidos é um fator chave para facilitar (ou atrapalhar) a transferência de conhecimento prático. Assim, a transferência de saber prático é um processo complexo, que não pode ser transferido, mas aprendido. Contudo, a socialização pode facilitar a transferência de saber prático.

Outra área do conhecimento em destaque é o saber científico que se estabelece em pesquisas. A busca do conhecimento científico surgiu da necessidade de o ser humano querer saber como as coisas funcionam, em vez de apenas aceitá-las passivamente. Com este tipo de conhecimento o homem começou a entender o porquê de vários fenômenos naturais e com isso passou a intervir cada vez mais nos acontecimentos ao seu redor, conforme Carvalho (1997).

Quanto ao saber tecnológico, esse é um fator fundamental na evolução humana. A história da tecnologia é quase tão velha quanto a história da humanidade, e existe desde quando os seres humanos começaram a usar ferramentas de caça e de proteção.

No entanto, Ferkiss (1972) entende que afirmar que a mudança tecnológica seja o fator central que define a existência humana não é dizer que a tecnologia seja a única variável independente na civilização humana. Nesse sentido, o autor afirma que a tecnologia é uma forma organizada, capaz de afetar o meio ambiente físico ou social, e que pode ser assimilada e comunicada a terceiros. É geralmente eficiente, independentemente das atitudes pessoais, qualidades ou talentos dos que a manipulam.

Todavia, tanto a produção científica e tecnológica quanto os demais conhecimentos estão organizados e difundidos basicamente por instituições educativas e de pesquisa. Nelas, concentrase o saber separado do trabalho manual, consolidando-se a divisão entre a teoria e a prática.

Mourão, N.M.; EngLeR, R.C. 


\section{DEFINIÇÕES DE TECNOLOGIA APROPRIADA E SOCIAL}

$\mathrm{Na}$ evolução da humanidade está inserido o processo de desenvolvimento da tecnologia que, consequentemente, gerou as tecnologias apropriadas. A definição de tecnologia apropriada está inserida nos termos de princípios gerais. Ou seja, a palavra apropriada significa que a tecnologia deve ser ajustada a algum propósito ou a um determinado uso específico. "Isso levanta a questão: apropriada a quê? E leva, portanto, à necessidade de examinar a apropriabilidade da tecnologia para cada situação específica" (RODRIGUES; BARBIERI, 2008, p.1072).

Goldemberg (1978) define o termo tecnologia apropriada como processo deestabelecimento dos efeitos sociais e ambientais de uma tecnologia proposta, antes que ela seja desenvolvida, e a tentativa de incorporar elementos benéficos nas várias fases de seu desenvolvimento e utilização.

A falta dos critérios que definam especificamente os âmbitos de apropriação induz o uso de modo indiscriminado da expressão tecnologia apropriada, levando em consideração que a tecnologia é sempre apropriada a alguma função ou a alguma coisa. Desta forma, uma tecnologia, para ser considerada apropriada, deve apresentar os seguintes aspectos sociais e econômicos: atender às necessidades das camadas mais pobres da população; preservar o meio ambiente; adequar-se aos recursos naturais disponíveis; utilizar de fontes de energia disponíveis no local de sua aplicação, conforme Rodrigues e Barbieri (2008) apud Willoughby (1990).

O Instituto de Tecnologia Social (ITS) Brasil define a tecnologia social como conjunto de técnicas e metodologias transformadoras, desenvolvidas e/ou aplicadas na interação com a população e apropriadas por ela, que representam soluções para inclusão social e melhoria das condições de vida (ITS, 2009).

Tal definição reflete a correlação de forças existente no conjunto ideologicamente heterogêneo de atores envolvidos com a Tecnologia Social, o qual abriga desde os que entendem a Tecnologia Social como um elemento das propostas de Responsabilidade Social Empresarial até os que labutam em prol da construção de uma sociedade socialista. (DAGNINO, 2011, p.1).

Para que os resultados da tecnologia social se estabeleçam, deve-se possibilitar a apropriação pela sociedade. De modo geral, os pesquisadores consideram Mahatma Ghandi, líder da Índia entre os anos de 1924 e 1927, como precursor do uso de tecnologias sociais em comunidades. Ele revolucionou o processo de fiação manual como resistência contra as injustiças sociais prevalentes naquele país. A roca de fiar manual tornou-se o primeiro equipamento tecnologicamente social e apropriado, utilizada para produção dos fios e dos tecidos para os hindus. "O pensamento de reformadores daquela sociedade estava voltado para a reabilitação das tecnologias tradicionais, praticadas em aldeias como estratégia de luta contra o domínio britânico" (DAGNINO, 2004, p.19).

\section{A TECNOLOGIA SOCIAL E AS RELAÇÕES DE TRABALHO}

A história do desenvolvimento da humanidade mostra a importância da tecnologia na configuração das relaç̃oes de trabalho e econômicas, no meio ambiente e na vida dos povos. As tecnologias sociais se estabelecem em processos metodológicos específicos que atendam à solução de uma ação social. A definição de ação social, presente nas análises de Weber (1999), demonstra uma ênfase sociológica na conduta que o ator subjetivamente conduz para o comportamento de outro, ou seja, essa ação social pode ser orientada para o comportamento de outro indivíduo. 
Nem todo tipo de contato entre pessoas tem caráter social, senão apenas um comportamento que, quanto ao sentido, orienta-se pelo comportamento de outras pessoas. Um choque entre dois ciclistas, por exemplo, é um simples acontecimento do mesmo caráter de um fenômeno natural. Ao contrário, já constituiriam "ações sociais" as tentativas de desvio de ambos e o xingamento ou a pancadaria ou a discussão pacífica após o choque (WEBER, 1999, p.14).

A conduta de um grupo, que define e estabelece suas prioridades e como resolver suas questões, pode ser estimulada pelas iniciativas de um ou mais membros do grupo. Todo fato social, para Durkheim (1995), é dotado de um caráter de generalidade sem que isso caracterize que um fato ocorrido em uma sociedade, necessariamente, não será o mesmo em outra, e que as questões relacionadas ao mesmo serão tratadas com os mesmos métodos. Certamente, como um pensamento em todas as consciências individuais não são por isso fatos sociais, nesse caso a generalidade não serve para caracterizar o fato social.

Salomon et al. (1993) relatam, no entanto, que na visão de Weber, em relação ao trabalho, os indivíduos atuam por diferentes razões. Distingue quatro motivações analiticamente diferentes para o trabalho: a da ética econômica tradicional; a da ética econômica carismática; a da ética prática racional; e a da ética econômica racional.

Os métodos de vida, necessidades e escolhas, são diversos em cada cultura. Uma ordem de fatos que apresentam características muito especiais: consistem em maneiras de agir, de pensar e de sentir, exteriores ao indivíduo, e que são dotadas de um poder de coerção em virtude do qual esses fatos se impõem a ele.

\section{O TRABALHO ARTÍSTICO DE TOBBE MALM}

Tobbe Malm ${ }^{4}$ nasceu e foi criado em uma cidade mineradora da Suécia, Norberg, em 1960. Norberg é uma pequena e antiga cidade mineira sueca. As explosões nos túneis de minas eram constantes. As pessoas na cidade eram habituadas aos trabalhos com o minério de ferro e com a fumaça presente no céu diariamente.

Malm cita como essa perpétua presença da mineradora durante sua infância influenciou sua vida e seu trabalho. A indústria de alto-forno encerrou suas atividades em 1981. Depois disso, a natureza se arrasta ao longo dos prédios em ruínas, recuperando o controle sobre seu domínio. A beleza inerente a esta destruição atinge Tobbe. Assim, seu trabalho é caracterizado por explorações sobre o seu território de origem e sua cultura de trabalho com o metal.

O trabalho, apresentado na experiência de vida de Tobbe, personifica a importância da tecnologia, do mundo econômico, sua influência crescente nas regiões mais diferentes da sociedade. Observa-se, conforme Cardoso (2001), que é preciso muito esforço humano para criar instrumentos que modificam a vida das pessoas.

Conforme Canto (2016), a série teve seu início quando Tobbe Malm encontrou alguns parafusos bem rústicos num celeiro em Bergslagen, na Suécia. Ao observá-los, ele identificou que as cabeças e as pontas poderiam se relacionar aos membros do corpo de uma pessoa, com qualidades humanísticas. Sentiu vontade de coletá-los para levá-los ao fogo para torná-los maleáveis e fáceis de girar, dobrar e moldar. A partir de então, o ferreiro criou relações, encontros

4CONTEMPORARYARTCURATOR.COM.Tobbe Malm. Postadoem 20 out.2015. Disponívelem:<http://www.contemporaryartcurator. com/tobbe-malm/>. Acesso em: 10 jul. 2016.

Mourão, N.M.; EngLeR, R.C. 
e situações diversas nas quais, histórias sobre dor, prazer, acolhimento, lamentação e humor são representadas por meio das peças, que antes eram totalmente desprovidas da relação humana de emoção. Dessa forma, uma espécie de poesia foi criada, o que dá sentido ao título da série Bolt Poetry (Poesia dos Parafusos).

É importante salientar que a relação usuário-produto sempre inclui o outro de alguma forma, seja fisicamente, seja em pensamento, de acordo com Damazio (2005), ou seja, os produtos não existem fora das relações sociais. É pouco provável que alguém, ao se deparar com um parafuso, consiga sentir alguma emoção. No entanto, Canto (2016) relata que um parafuso, nas mãos de Tobbe Malm, parece ganhar vida e emoção.

A busca pela emoção está associada a um constante desejo de bem-estar, de formas de vida que privilegiam sua ação individual dentro de seu grupo e, por esse motivo, o indivíduo torna-se um consumidor de produtos que cada vez mais lhe tragam um bem-estar emocional. Essa busca por um bem-estar faz com que ele deixe, cada vez mais, seus padrões antigos à procura de outros novos, o que antes lhe servia hoje já não significa mais, é necessária uma nova construção cultural quase que imediata. (RIBEIRO, 2009, p.35).

Como ferreiro, o artista dá formas humanizadas a parafusos e peças de metal, que independente de suas formas, parecem carregadas de emoções.

A Figura 1 é imagem do trabalho de Tobbe Malm, na qual a composição em parafusos representa a figura de um genitor (parafuso) com seu filho no colo (prego pequeno). Série denominada Bolt Poetry.

FIGURA 1: O parafuso é o genitor e o preguinho é o filho. Série Bolt Poetry.

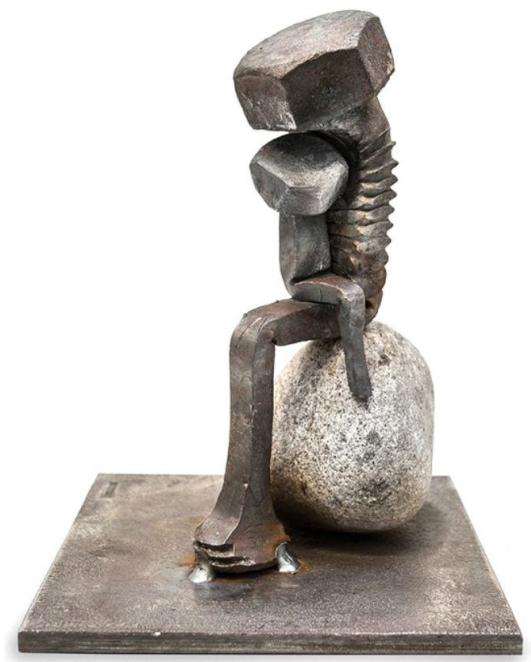

Fonte: <http://tobbemalm.com/>

E a imagem do trabalho artístico de Tobbe Malm, na Figura 2, representa a solidariedade humana.

Malm mudou-se para Oslo, na Noruega, em 2008, e após os ataques terroristas em Oslo e Utøya, em 22 de julho de 2011 , criou o Projeto Herrero International Iron Rose, inspirado pelas numerosas rosas colocadas nas ruas, após o trágico evento, conforme site DT.SE 5 .

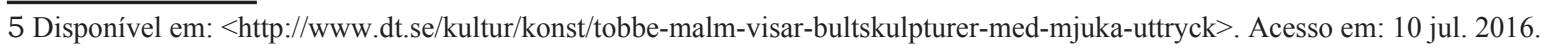


Tobbe trabalhou com os sobreviventes, seus familiares e pessoas próximas às vítimas para forjar rosas de ferro. O processo artístico oferece a oportunidade para a cura por meio da criação de um espaço onde a dor pode ser compartilhada e, portanto, mais leve. Para cada rosa forjada, por meio dessa tecnologia social, outra é acrescentada à crescente coleção de rosas de ferro que chegam de ferreiros internacionais. O projeto foi organizado em um grupo do Facebook ${ }^{6}$.

\section{FIGURA 2: Representação da solidariedade humana. Série Bolt Poetry.}

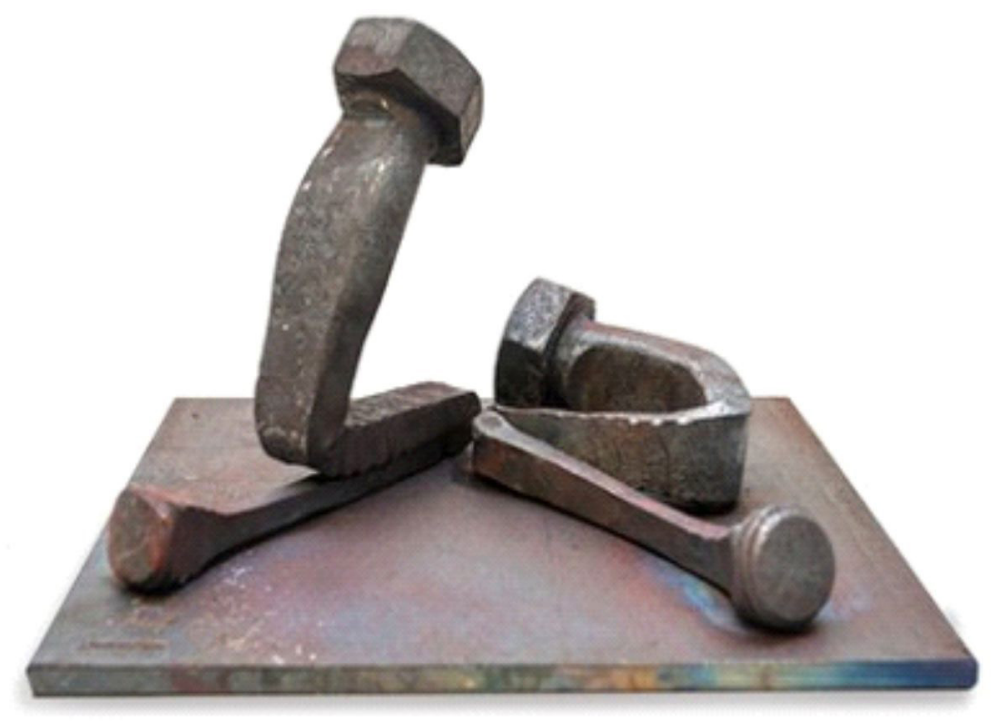

Fonte: <http://tobbemalm.com/>

Desde agosto de 2011, 900 rosas foram confeccionadas por ferreiros de mais de 25 países, em apoio ao projeto. Na Figura 3, algumas das rosas de ferro confeccionadas pelo projeto Iron Roses em 2015.

\section{FIGURA 3: Rosas em ferro. Projeto Iran Roses.}

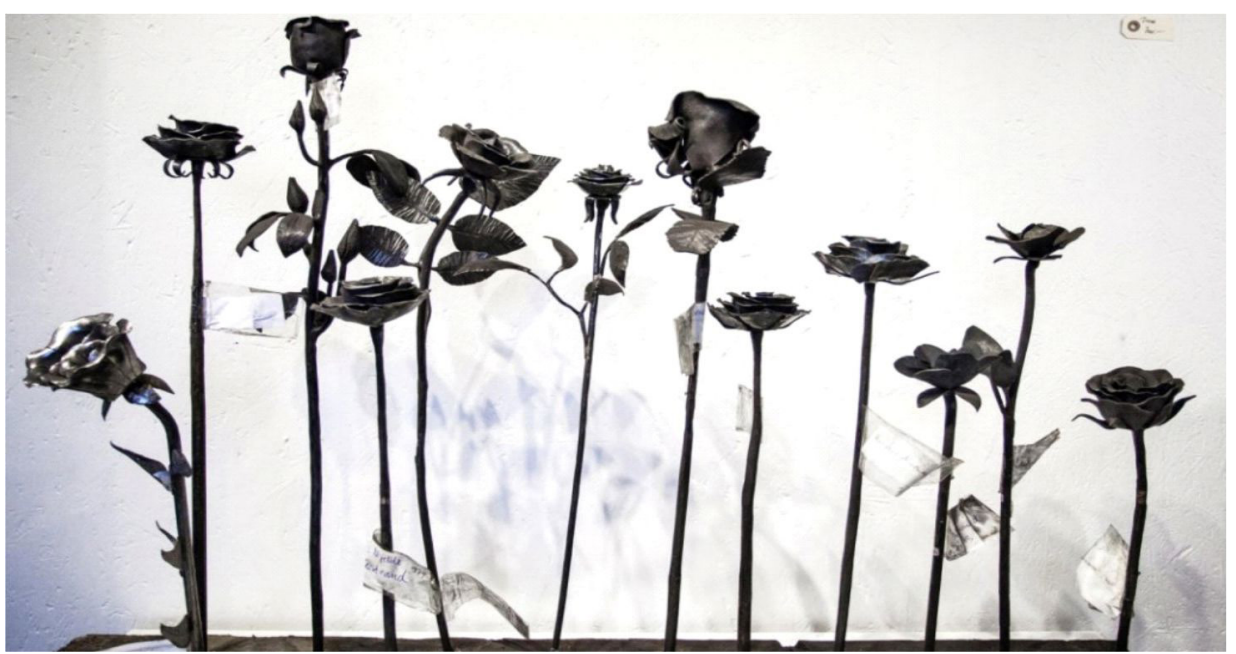

Fonte: $<$ http://tobbemalm.com/>

As tecnologias sociais são utilizadas como soluções para problemas sociais e podem ser replicadas por outros grupos sociais. A tecnologia social de apoio emocional, por meio da técnica

6 Disponível em:<http://www.jernmalm.com/iron-rose-for-norway>. Acesso em: 10 jul. 2016. 
de forjar o ferro, destinada aos sobreviventes e familiares do evento, foi replicada. Professores do programa de engenharia em Wisconsin, EUA realizaram um projeto onde os alunos confeccionaram 100 rosas de ferro para o memorial na Noruega. Na Croácia, um ferreiro ofereceu um curso livre àqueles que desejassem confeccionar as rosas, conforme Jensen (2016).

Tobbe foi premiado com o 2014 Alfred Habermann Memorial Prize. Várias instituições já divulgaram o projeto no mundo. Recentemente, foi apresentado no Portugal Steel Conference Seminário Portugal Steel, conforme página do Facebook, TobbeMalmMetalArt. Contudo, com a série Bolt Poetry e o projeto Iron Roses, são propostas que, na solidez do ferro, em técnica e tecnologia, emocionam e proporcionam mudanças na vida das pessoas.

\section{CONSIDERAÇÕES FINAIS}

Nesse estudo, foram apresentadas algumas das temáticas que se associam à tecnologia social e buscaram-se relacionar os conteúdos abordados ao trabalho artístico de Tobbe Malm.

Os autores apresentados pela pesquisa e as temáticas apontam que, por meio da tecnologia, transformações materiais ocorrem efeitos para vida humana. Pucci (1994) trata das atividades que geram produtos impactantes e Castells (2009) relata as mudanças causadas pela tecnologia em comunicação. Nas investigações da natureza da tecnologia, Gianolla (2008) e Arthur (2009) apresentam divisões temáticas que esclarecem as funções das atividades humanas. Não há existência física do ser humano sem o uso da matéria.

Em prol do capitalismo, a existência da sociedade está imersa no sistema de produção, que também gera um processo acelerado. Em tese apresentada por Halévy (1961), a humanidade tem a sensação de viver em uma época de aceleração crescente e de rápidas mudanças, geradas pelo domínio do trabalho no cotidiano. A carência de tempo na contemporaneidade tornou-se uma expressão cultural, comum e popularizada nos ambientes urbanos.

Além disso, Lins (2003) expõe que em relação à existência humana ocorre a tecnologia do aprendizado com método do saber prático, sob as bases da tradição do fazer e o saber científico.

Contudo, as tecnologias são criadas e utilizadas pelo homem, nas palavras de Ferkiss (1972), mas permanecem pelos métodos de apropriação, conforme Goldemberg (1978), sob os efeitos socioambientais de uma tecnologia proposta.

Em relação ao trabalho, Weber (1999) expõe que as pessoas atuam por razões diferentes e que todo encontro humano é social. O encontro ou confronto não caracteriza um fato social, mas todo fato social é dotado de um caráter humano, pois são questões relacionadas ao mesmo, conforme Durkheim (1995).

No entanto, ao relacionar o trabalho de Tobbe Malm com as temáticas associadas à tecnologia social, foi observado que em cada etapa de vida do artista suas iniciativas e seus projetos se convergem aos conteúdos. A relação de transformação da forma do parafuso com o saber prático e científico condiz com a associação do emocional. Essa relação é produzida pelo trabalho artístico, utilizando o mesmo material proposto, ou seja, o ferro. O interessante é a reflexão de que um parafuso carrega uma parcela do processo de evolução da tecnologia. Contudo, a intervenção do artista associa ao parafuso outra vertente da vida humana. As tradições, a cultura e a emoção tornam os projetos artísticos de Tobbe Malm um trabalho inovador. 
Projetos como os apresentados por Tobbe Malm mostram a importância da apropriação de técnicas simples pela população para assistir ao processo de recuperação do ambiente da sociedade, em face de problemas comuns que atingem a todos sem distinção de classe, cor, religião, orientação sexual, situação econômica ou profissão. Como artista, Tobbe Malm poderá ainda contribuir muito para o incentivo entre o conhecimento e a produção humana. Há muito a ser construído se a sociedade partir da simplicidade e cidadania oriundas das tecnologias sociais.

\section{REFERÊNCIAS}

ARTHUR, W. B. The Nature of Technology: What it is and how it evolves. Nova York: Free Press, 2009.

CANTO, F. Parafusos 'humanizados' expressam emoções na série Bolt Poetry, de Tobbe Malm. In: Ideiaquente. Postado em: 02 maio de 2016. Disponível em: <http://www.ideiaquente.com/2016/05/ bolt-poetry-tobbe-malm.html>. Acesso em: 31 mar. 2017.

CARDOSO, T. F. L. Sociedade e Desenvolvimento Tecnológico: uma abordagem histórica. In: Educação Tecnológica: desafios e perspectivas. São Paulo: Cortez Editora, 2001.

CARVAlho, M. C. M. de (Org.). Construindo o Saber. Metodologia Científica. Fundamentos e Técnicas. 6. ed. Campinas: Papirus; 1997.

CASTELlS, M. A Sociedade em Rede. A Era da Informação: Economia, Sociedade e Cultura. 5. ed. São Paulo: Paz e Terra, 2009.

COSTA, A. B. (Org.). Tecnologia Social e Políticas Públicas. São Paulo: Instituto Pólis. Brasília: Fundação Banco do Brasil, 2013.

DAGnino, R. (Org.) Tecnologia social: uma estratégia para o desenvolvimento. Rio de Janeiro: Fundação Banco do Brasil, 2004.

DAMAZIO, V. Artefatos de memória da vida cotidiana: um olhar interdisciplinar sobre as coisas que fazem bem lembrar. 2005. 285f. Tese (Doutorado em Ciências Sociais) - Universidade do Estado do Rio de Janeiro, Rio de Janeiro, 2005.

FERKISS, V. C. O homem tecnológico: mito e realidade. Rio de Janeiro: Zahar Editores, 1972.

GIANOLLA, R. M. Tecnologias, Educação e seus sentidos: o movimento de um grupo de pesquisa sobre Interdisciplinaridade - GEPI. 2007. 173f. Tese (Doutorado em Educação) - Pontifícia Universidade Católica de São Paulo, São Paulo, 2008.

GOLDEMBERG, J. Tecnologia apropriada. Encontros com a Civilização Brasileira. Rio de Janeiro, n.3, 1978.

HALEVY, D. Essai sur l'accélération de l'histoire. 2. ed. Paris: Fayard, 1961.

JENSEN, S. A. Tem 900 rosas de ferro em stock. 2016. Disponível em: <http://www.budstikka.no/ kultur-og-underholdning/barums-verk/kunst/har-900-jernroser-pa-lager/s/5-55-329161>. Acesso em: 01 jul. 2016.

KAZAZIAN, T. (Org.). Haverá a idade das coisas leves: design e desenvolvimento sustentável. São Paulo: SENAC, 2005. 
LINS, S. Transferindo Conhecimento Tácito. São Paulo: E-papers, 2003.

MANZINI, E. Design para a inovação social e sustentabilidade: comunidades criativas, organizações colaborativas e novas redes projetuais. Rio de Janeiro: E-papers, 2008.

MAZOYER, M.; ROUDART, L. História das agriculturas no mundo: do neolítico à crise contemporânea. São Paulo: UNESP, 2008.

MIRANDA, A. L. Da natureza da tecnologia: uma análise filosófica sobre as dimensões ontológica, epistemológica e axiológica da tecnologia moderna. 2002. 161f. Dissertação (Mestrado em Tecnologia) Centro Federal de Educação Tecnológica do Paraná, Curitiba, 2002.

PUCCI, B. (Org.) Teoria Crítica e Educação: a questão da formação cultural na Escola de Frankfurt. Rio de Janeiro: Vozes, 1994.

RIBEIRO, R. Design, Emoção e Objetologia: estudo contemporâneo sobre as relações de afeto entre o homem e os objetos - produtos. 2009. 78f. Dissertação (Mestrado em em Design) - Universidade Anhembi Morumbi, São Paulo, 2009.

SANTOS, M. A natureza do espaço - técnica e tempo, razão e emoção. São Paulo: Hucitec, 1999.

SANTOS, M. Por uma outra globalização: do pensamento único à consciência universal. São Paulo: Record, 2000.

ZUBEN, N. A. von. A filosofia e a condição humana. Pro-posições, Campinas, vol. 4, n.3, p.07-2 1, nov. 1993. 